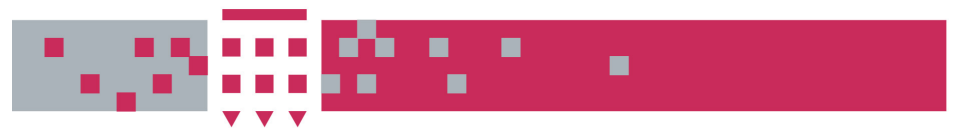

\author{
WestminsterResearch \\ http://www.wmin.ac.uk/westminsterresearch
}

\title{
The changing nature of rail freight in Great Britain: the start of a renaissance?
}

\section{Allan G. Woodburn}

School of Architecture and the Built Environment

This is an electronic version of an article published in Transport Reviews, 21(1), pp. 1-13, January 2001. Transport Reviews is available online at:

http://www.journalsonline.tandf.co.uk/openurl.asp?genre=article\&issn $=01$ 44-1647\&volume $=21$ \&issue $=1$ \&spage $=1$

The WestminsterResearch online digital archive at the University of Westminster aims to make the research output of the University available to a wider audience. Copyright and Moral Rights remain with the authors and/or copyright owners. Users are permitted to download and/or print one copy for non-commercial private study or research. Further distribution and any use of material from within this archive for profit-making enterprises or for commercial gain is strictly forbidden.

Whilst further distribution of specific materials from within this archive is forbidden, you may freely distribute the URL of WestminsterResearch. (http://www.wmin.ac.uk/westminsterresearch).

In case of abuse or copyright appearing without permission e-mail wattsn@wmin.ac.uk. 


\section{BIOGRAPHY}

ALLAN WOODBURN is a Lecturer in Transport in the School of the Built Environment at Napier University in Edinburgh, where he also undertakes transport research and consultancy work for the Transport Research Institute. He has specialised in freight transport and logistics research, particularly examining modal choice issues, and is currently working on his Doctorate on the development of rail freight services in Great Britain. 


\title{
THE CHANGING NATURE OF RAIL FREIGHT IN GREAT BRITAIN: THE START OF A RENAISSANCE?
}

\author{
By Allan G. Woodburn \\ Transport Research Institute, Napier University, 10 Colinton Road, \\ Edinburgh, EH10 5DT, UK.
}

Tel: 0131455 2210; Fax: 0131455 2239; email: a.woodburn@napier.ac.uk

\begin{abstract}
This paper reports on ongoing research into the potential for rail freight service developments to achieve a significant modal shift away from road towards more sustainable modes of transport for freight movements. It is based on the analysis of comprehensive databases of rail freight flows in Great Britain in 1991 and 1997, a period in which there has been dramatic upheaval of rail freight services. This reveals that traffic volumes in early 1997 were still below those in early 1991, but that many new flows were beginning to manifest themselves as a result of traffic gains by the newly privatised operators who have been actively seeking new custom. Some of these flows are ones that were lost from rail during the period of decline, but it is clear that a significant volume of traffic gained is entirely new to rail. Finally, the need for more research on the interactions between these supply-side developments and logistical restructuring is highlighted.
\end{abstract}

Keywords: Rail freight, modal shift, privatisation, environment 
Abbreviated title: Prospects for British Rail Freight 


\section{Introduction}

There is growing concern about the effects of the increasing use of road freight, in particular the negative impacts that it has on the environment. This has led to demands for greater use to be made of modes that are less environmentally damaging, such as rail and coastal shipping. This paper forms part of ongoing research, for which there are two main objectives. The first of these is to determine the interactions between logistical structure and choice of rail as a mode for freight movement. There have been many logistical changes that potentially could affect the modal split decision. For example, changes in the location of activity, the structure of manufacturing and distribution networks, the trading relationships between firms and the scheduling of production and distribution may all be important factors that influence mode choice for freight movements. Following on from this is the other main objective: to identify means by which logistical changes can assist in increasing the share of freight moved by rail. This is of direct importance to rail freight service providers, whose survival may depend upon attracting new traffic to their services. It is also of importance to those other parties who are interested in transferring freight from road to rail. These may include environmental campaigners who wish to see goods transferred by less environmentally damaging means, local and national government departments who are keen to reduce road maintenance costs, or even the general public as a whole, keen to see fewer large lorries on the roads. 
The main aim of this paper is to report on the analysis of changes in the provision of rail freight services in Great Britain since the early 1990s. This analysis will be developed in future research to enable identification of the key trends and areas where there may be potential for rail to increase its share of the market along the lines recommended by the Royal Commission on Environmental Pollution (RCEP, 1994) which advocates a three-fold increase in market share by 2010 .

\section{Background}

Prior to considering detailed changes in the supply of rail freight services, it is advantageous to provide an overview of the main developments that have occurred in recent years, many of which have been influenced by factors external to the rail industry. Figure 1 shows the trends in rail freight volumes since the early-1980s, disaggregated into coal and other (i.e. non-coal) movements. The volume of rail freight moved has been in long-term decline since the 1950s, this trend largely continuing over the last 15 years though with a shorter-term cyclical trend within the longer-term downward one. The long-term decline has been due mainly to increased competition from road and the decline in heavy industry, compounded by a lack of interest from British Rail in keeping all but the most lucrative bulk traffic on rail. This concentration on bulk trainload traffic is discussed below, but this was clearly not a strategy for rail freight growth, or even stability, given that the main bulk markets of coal and steel have 
suffered contraction, along with certain sectors of the petroleum and construction industries in which rail has traditionally had a healthy market share.

The cyclical trend is largely influenced by the state of the British economy, which was in recession in the early-1980s and again in the early- to mid-1990s. Traffic levels increased in the interim, reflecting the general level of economic activity but more particularly the booming construction industry for which rail plays a significant role in moving raw materials. It is quite clear that the 1990s trough was deeper than that in the 1980s, emphasising the overriding downward trend. The effect of the miners' strike in 1984 is clear, when virtually no coal movement by rail took place. This clearly had a major effect on the level of rail freight in the 1984/85 period. It also affected subsequent coal movements due to the decline in the number of operational collieries and the reluctance to switch traffic back to rail that had been transferred to road. More recently, changes in the power generation industry have led to a substantial decline in the use of coal, though a greater proportion of the coal burned now is imported or transported over longer distances from domestic sources within Britain. This has actually had benefits for rail volumes, since the decline in tonnage has been offset by an increase in the average length of haul.

(Insert Fig. 1 here)

For most of the discussion in this paper, the analysis focuses on non-coal traffic, since coal flows differ significantly from other traffic types. Surprisingly, there has been little change in non-coal traffic since 1982/83, though there have been 
variations. Specifically examining the latter period, which is that focused upon by the original databases discussed later, there was an overall decline in both rail freight tonnages lifted and moved between 1990/91 and 1996/97; these years are the most comparable ones to the two databases, which are for January 1991 and January 1997 . With coal traffic excluded, tonne kilometres actually increased by $7 \%$, though this conceals the fact that decline occurred at the start of the time period, coinciding with the withdrawal of Speedlink services discussed below, followed by stabilisation for several years. The first signs of an upturn in business can be seen towards the end of the period.

The 1990s have been a time of significant change for rail freight, particularly for wagonload traffic (i.e. less-than-trainload consignments). Since the 1955 Modernisation Plan, which led to a major restructuring of all aspects of the rail network, British Rail had been focusing on moving freight in block trainloads, though with attempts to maintain a wagonload presence through the development of the Speedlink network. Analysis in the late-1980s, however, showed that only $20 \%$ of Speedlink's costs were associated with running trunk hauls, whereas trip working (i.e. local distribution) accounted for 50\% and marshalling the other 30\% (Rhodes and Shannon, 1991a). This led to British Rail deciding to withdraw from virtually all wagonload rail freight operations.

When Speedlink was withdrawn in 1991 there were over 75 daily trunk services, connecting the remaining marshalling yards across the British Rail network. Trip workings served over 100 terminals on a regular basis, with a similar number handling irregular consignments. Many locations continued to be served 
by block trainloads after withdrawal of Speedlink, but in other cases terminals closed to rail traffic. The focus after 1991 was primarily on running trainloads directly from origin to destination, with very few wagonload services remaining. Trainload Freight was responsible for virtually all flows except Freightliner, international and automotive services, these being operated by Railfreight Distribution.

The structure of rail freight was radically altered in 1994 when, in preparation for transfer to the private sector, the Trainload Freight businesses were reorganised on a geographical basis rather than the existing commodity groupings. Three new operating businesses were established, each covering a separate part of the British mainland. Operationally, little change occurred after this reorganisation, since most flows operated fairly autonomously. There was limited scope for combining different commodity flows traversing similar routes, but this was fairly negligible. The businesses were offered for sale in 1995 amid controversy, since many experts believed that rail freight operators should not have to compete with each other, since their main competitor was the lorry. It was argued that economies of scale in rail freight provision should be taken advantage of by having one single domestic operator. Indeed, all three were handed over to Wisconsin Central, a U.S. private railroad operator, in February 1996, to be operated under common ownership as English Welsh and Scottish Railway (EWS). Furthermore, Wisconsin Central had already taken control of Rail Express Systems, the provider of Royal Mail services and in 1997 added Railfreight Distribution to its portfolio. Thus, virtually all non-passenger 
services are now in the hands of one operator, the main exception being Freightliner.

\section{Method}

This paper is concerned with the analysis of changes of the considerable changes in service provision since the early-1990s and focuses on two databases that have been constructed to provide as comprehensive data as possible at the particular points under consideration (i.e. January 1991 and January 1997). This section discusses these databases, providing details of the information collected and its sources and outlining the suitability of such a method for analysing changes in rail freight activity.

The information collected for the databases for each rail freight service was gained from a number of sources. The two points in time were chosen due to their significance in terms of the changing provision of services, particularly wagonload, and because of the relative ease of obtaining comprehensive information. In early-1991, there was considerable interest in rail freight services due to the imminent cessation of Speedlink services and the effects that this was likely to have on traffic flows, whereas in early-1997 rail privatisation meant that much discussion and analysis of services was taking place in the railway press. The main sources of data included Rhodes and Shannon (1991b) and Freightmaster (1997), both of which contain much general information about a large proportion of services. In an attempt to ensure as complete coverage as 
possible, further sources were utilised, notably the railway press and (for 1997) the in-house journal of EWS. While the main data sources were aimed primarily at the rail enthusiast market, they nevertheless provide invaluable details of traffic flows.

\section{Database information}

The main information in the databases includes:

- origin and destination of service: to allow analysis of changes in the number of points served by rail freight services

- departure time from origin and arrival time at destination

- intermediate stopping points for detaching or uplifting traffic

- service frequency: i.e. number of days per week

- days of operation

- commodity/sector: in 1991, flows were classified according to the operating sector; 1997 flows have been classified according to commodity, providing more detail than sector alone but still allowing comparison between the two

- nature of service: i.e. whether loaded, empty or mixed

- operator of service (1997 only): to provide details of post-privatisation responsibility for service provision; prior to privatisation, services were operated by the different sectors

- other relevant information: for example, whether or not the service runs every day it is scheduled to or only as required 
Unfortunately it was not possible to obtain complete information for all traffic flows that were identified, but in almost all cases the crucial details of origin, destination, service frequency and commodity/sector were available. The databases contain information about all freight services, with the exception of those operated on behalf of the Royal Mail and those for infrastructure maintenance. The former were excluded due to the difficulties in obtaining reliable information for 1991 and the latter are extremely variable in terms of their origins, destinations and service frequencies and, in any case, are involved in carrying materials for the rail industry itself rather than external customers.

The choice of time periods for the databases was to a large extent dictated by the availability of information about traffic flows. It is believed that the use of these two points (early-1991 and early-1997) is suitable for the purposes of this research, since the main aim is to analyse changes in the supply of rail freight services. By choosing January in both of the years as the precise point at which the database information is based, any seasonal variations in traffic are controlled for. This is an important factor, since many rail freight flows are highly seasonal. For example, power station traffic is far greater during the winter when demand for electricity is at its highest, while automotive traffic peaks in early summer (prior to August deliveries of new cars). It is acknowledged that there may be other factors that will affect how representative the databases are of the overall time period. By taking specific points in time, there are dangers that they will not give a true reflection of general changes between the early-1990s and the present day. Certainly rail freight volumes are affected by external factors, for 
example the level of activity in the construction industry or changes in the storage of petroleum products at customers' sites. The effects of many such changes are discussed in NERA (1997). On the whole, though, the main changes in rail freight flows over a relatively short period appear to be the result of supply-side changes.

\section{Comprehensiveness of the databases}

More importantly, an attempt has been made to assess the comprehensiveness of the databases, as any analysis would be of little significance if they were found not to include the vast majority of services. Table 1 compares tonnes lifted based on the summation of the individual entries in the databases with the published gross annual statistics. This comparison is necessarily approximate and relies upon a number of assumptions:

- Coal traffic has been excluded, due to the lack of detailed information on flows for 1991. At that time, there were major short-term fluctuations in flows between particular origins (mainly collieries) and destinations (predominantly power stations), due to the greater number of collieries. Since then, there has been a reduction in the number of operational collieries, so the pattern of flows is more stable.

- It was necessary to translate the number of database entries into a more meaningful figure such as number of loaded services per week. The former 
number is of little use as it does not detail the actual number of services operating in a week. For the majority of services the days of operation are fixed, but for a significant minority service frequency varies depending on the availability of traffic. In the case of these services, based on observations by the author of freight services in 1997, it has been assumed that they operate on $50 \%$ of the potential number of days for which they are timetabled. In 1997, 201 out of 1080 database entries (i.e. 19\%) operated on such an 'as required' basis, whereas in the 1991 database none of the entries operated on this basis. The reason for this difference is not clear, though two main factors are probably relevant. The growing commercial awareness in the rail industry, particularly of the newly privatised operators, is likely to be leading to greater flexibility in service provision now compared to 1991, when services tended to operate to a much more rigid pattern. Secondly, changed procedures in the provision of track access as a result of the formation and subsequent privatisation of Railtrack may have resulted in more train paths than required being requested by the operators, giving them the option to take up these booked paths if traffic flows justify the provision of a service. The establishment of these paths in the Railtrack working timetable makes it easier for an operator to run a particular service, rather than having to go through the cumbersome procedures to obtain a special path from Railtrack each time it is required. Nevertheless, it is almost certain that some services operated 'as required' in 1991, so differences in the standard of information may exist between these two databases due to the use of different sources of data for the two years. While this may have a slight impact on the accuracy of the time 
series analysis of the databases, there is unfortunately no way of quantifying this degree of error.

- It was not always possible to determine whether or not services were loaded, empty or mixed, particularly in 1991 when details of individual traffic flows were harder to obtain. For bulk trainload services, it has been assumed that they are loaded in one direction, with the corresponding return working being empty. Due to the nature of these flows, it is extremely rare for loaded workings to operate in both directions though where it is known to occur (e.g. some steel flows) this has been incorporated into the databases. For non-bulk operations (e.g. Speedlink, Freightliner) all services have been assumed to be loaded for the purposes of calculating the approximate number of services per week. These networks for non-bulk traffics do (or did) exist to cater for flows in both directions along a route, so the majority of services are likely to carry a mixture of loaded and empty wagons, though the relative proportions of each will vary from service to service depending on traffic flows and are indeterminable. While many of the trip workings for wagonload services are likely to be empty in one direction, the lack of information means they are classed as loaded in the databases. This method of classification is at least consistent between the two time periods under consideration and the proportion of services involved out of the total number is relatively low.

- To convert from number of loaded services per week to tonnes lifted required an assumption on the average payload of a freight train. Based on recent observation, it has been assumed that 500 tonnes is a reasonable 
approximation of payload. This takes account of the fact that the main types of wagon have capacities ranging from 8 tonnes up to 100 tonnes, with the average payload in the region of 30-40 tonnes (Marsden, 1984). The assumed average length of train is 15 wagons, though this again varies considerably depending on the commodity and flow characteristics and can range from 1 up to 50 wagons.

(Insert Table 1 here)

This comparison reveals that the estimates of tonnes lifted based on the databases actually exceed the published annual statistics for both years. While this may be a result of the assumptions outlined before being inaccurate, it is likely to reflect the fact that in some cases individual flows will be counted on more than one occasion due to staging of services or re-marshalling en route. This is particularly the case with the jumbo aggregates trains from the Mendip quarries to the South East of England, which are split into two or three portions in West London for local distribution, and with wagonload flows which may make use of a number of different services to get from origin to destination.

The fact that the degree of over-estimation is far greater for the 1991 database lends weight to the double-counting argument. This is because wagonload services, with their greater marshalling and trip working (and thus doublecounting of individual consignments), accounted for $32 \%$ of all database entries in 1991 (i.e. Speedlink services) compared with just 13\% in 1997 (i.e. Enterprise and Connectrail services). Enterprise services form the basis for the domestic 
wagonload network revival, discussed later, while the Connectrail network covers the small number of international wagonload services now operating through the Channel Tunnel. Another factor that may account for the higher degree of over-estimation in 1991 is the previous assumption that all non-bulk flows are loaded. This may result in the over-estimation of the average payload for some of these services, particularly for those where the majority of wagons in the train consist are being returned empty and would again have been more of an issue in 1991 due to this greater significance of wagonload freight.

Therefore, after taking these factors into account, it appears that the databases do provide a good representation of the actual flows at those points in time even though the volume estimates are not particularly accurate. On the whole, informal discussions with an EWS representative regarding the completeness of the 1997 database flows from, to and within Scotland suggested that the overwhelming majority of services were incorporated in that database.

\section{Major changes in rail freight services since 1991}

This section is concerned with the analysis of the database information. It reveals the extent of changes in commodity flows and locations served by rail freight, as well as discussing the effects on traffic volumes of the recent developments that have taken place as a result of the privatisation process. Much of the analysis focuses on Anglo-Scottish traffic and flows within Scotland, to allow more detailed discussion of the key changes that have been occurring. 


\section{Disaggregation by commodity}

It was clear from the analysis of the comprehensiveness of the databases, discussed above, that there has been a decline of $32 \%$ at the aggregate level in the number of loaded services being operated. It is possible to disaggregate by commodity grouping to allow more detailed analysis, this being shown in Table 2. The comparison of commodity types between the databases necessarily involved some assumptions being made on the classification of certain services. This is due to the reorganisations that have taken place between 1991 and 1997, which have meant that traffic flows are no longer allocated to particular sectors. However, in virtually all cases it is obvious which of the former sectors the service would have been allocated to.

(Insert Table 2 here)

It is clear that the overall decline has not been consistent across all commodity groupings. The greatest decline, both in relative and absolute terms, has been in the number of loaded non-bulk services. This is perhaps not surprising, given the withdrawal of the Speedlink network and subsequent focus on wagonload traffic. However, for the main trainload flows there have also been dramatic reductions in the number of services operated, with decreases of between (32\% and $44 \%)$. The scale of reduction is far greater than the decreases in tonnages carried for each commodity group, primarily resulting from the focus on the core traffic 
flows. The operation of many services has been simplified, with more direct terminal to terminal flows and less intermediate staging and marshalling of traffic, even for trainload flows. In addition, the introduction of new motive power has meant that heavier trailing loads are now possible, such as the increase in maximum tonnage from 1,500 to as much as 2,700 tonnes per train for some petroleum flows which resulted from the introduction of Class 60 locomotives during 1991 (Rhodes and Shannon, 1991a). The introduction of Class 60s, as well as 59/2s, made a huge impact on the movement of bulk products, in some cases resulting in a rationalisation in the number of services operated but without a decline in tonnage being carried.

The only sector to have shown an increase in the number of loaded services has been container, intermodal and automotive traffic. This covers all services operated by Freightliner and Railfreight Distribution. During the period under consideration, the Freightliner network has been rationalised with a reduction in the number of terminals served and the creation of a hub at Crewe and the number of automotive services has also declined slightly. The growth has occurred in intermodal services through the Channel Tunnel, which were introduced in 1995 and have grown at a fast enough rate to negate the losses in the other traffics. It is in the container/intermodal sector, as well as in wagonload freight, where future growth is most likely to occur.

\section{$\underline{\text { Terminal activity }}$}


Another key factor in terms of the degree of penetration of rail freight across the country is the number of locations served by regular services. In the 1991 database, there were 366 locations handling non-coal traffic; in 1997 this had decreased to 328 , a reduction of $10 \%$. This information should be treated with some caution, as it may not be a true representation of the actual number of locations receiving or dispatching traffic. This is because, in many cases, the information sources used for the databases do not distinguish between different terminals that are located in close proximity to each other. There has also been a reduction in the number of operational marshalling yards, where traffic flows did not actually originate or terminate in any case. However, this will have had only a very slight impact on the number of locations served. Perhaps more significantly, there were many terminals that in 1991 were supposedly still active and receiving Speedlink traffic for which no information has been found, so the scale of decline is probably greater than the $10 \%$ revealed by the databases. It may be possible to determine from other sources the number of additional terminals handling traffic, but this has not yet been achieved. It seems likely that many were receiving or dispatching traffic on an ad hoc basis rather than using regular timetabled services. Finally, the reversal of the downward trend in volumes had started to result in a small number of additional terminals being added to the network in late-1996, so the decline had possibly been more severe in the earlier years.

\section{The Scottish situation}


The changes can be seen in Table 3, which shows the number of locations in Scotland served by the different commodity flows. In each case, the total number of locations (as defined in the databases) is lower than the sum of the individual commodity totals. For example, in Aberdeen there are currently two terminals handling wagonload flows and another terminal for petroleum traffic, but these are shown as just one entry in the databases. The main purpose of the table, however, is to show how the number of locations served by rail in Scotland has changed. An intermediate database, for January 1995, was also constructed for Scotland to give an additional data series. Ideally, 1994 would have been chosen, since it is midway through the period under consideration, but comprehensive data for then were more difficult to obtain than for 1995 . The scale of reduction in number of locations served in Scotland has clearly been far greater than for Britain as a whole, with a 54\% decrease between 1991 and 1997. This decrease was concentrated in the early part of the period, with a slight increase taking place between 1995 and 1997 reflecting the upturn in traffic that has started to emerge, reinforcing the point made above.

The greatest decline in absolute numbers occurred in the non-bulk commodity category. Scotland was particularly hard hit by Speedlink's cessation, since a greater proportion of marginal non-bulk traffic flows than in the other regions had remained on rail until 1991 due to the long lengths of haul between Scotland and Central and Southern England. These flows consisted of small volume, often seasonal, movements to and from remote and dispersed locations of commodities such as grain, chemicals, food products and timber and very few of these were feasible for trainload movement. 
The three bulk sectors (i.e. Construction, Metals and Petroleum) also suffered major losses in the numbers of locations served. In the case of petroleum flows, this was due to BP's reorganisation of movements from its Grangemouth refinery after price rises from British Rail, which led to a number of flows switching from rail to road in the early 1990's. Similarly, the dramatic decline in the number of terminals served by metals traffic resulted from British Steel's decision to close Ravenscraig steelworks in 1992. This led to the virtual elimination of steel traffic in Scotland, as well as the loss of inward flows of raw materials to the steelworks. For construction traffic, over half of the terminals have ceased handling trainload flows since 1991. However, two of the terminals that were previously served by trainload flows are still receiving flows as part of the wagonload network, so are now included in the non-bulk grouping instead.

(Insert Table 3 here)

Overall in Scotland, to a greater extent than elsewhere in Great Britain, there was a substantial decline in the number of locations served by rail freight flows, though there are the first signs of a reversal in that trend. This is a result of the recent changes that have taken place as a result of the privatisation process for rail freight operations, which has started to encourage new trainload flows but, perhaps more importantly, has also looked to the expansion of wagonload flows as a key growth area. 


\section{$\underline{\text { Revival of wagonload services }}$}

In September 1994, Transrail (one of the three regional trainload freight companies) decided to revive wagonload rail freight and consolidate some of the smaller trainload flows that it was operating. This led to the setting up of its Enterprise wagonload network, the core network consisting of just 10 trunk services per day and with limited geographical coverage. Examples of flows that were incorporated into the Enterprise network included carbon dioxide from Fife to London, chemicals from Teesside and Cheshire to Ayrshire, timber from the Highlands to Deeside and china clay from Cornwall to Scotland, as well as internal rail infrastructure traffic. This basic network then provided the focus for attracting new custom and, by 1997, the network had expanded to cover all the major industrial and urban areas of Great Britain, with many of the original routes having seen considerable expansion in the number of services provided.

By 1997 there were 46 trunk wagonload services operating each day, with around 50 locations served by regular feeder workings and many more being served on an irregular or trial basis as traffic volumes expand. This network is therefore still significantly smaller than Speedlink was even in its final days, though the rate of growth has been rapid. Analysis of the databases reveals that there were approximately 1100 Speedlink services per week in January 1991, with only around 300 Enterprise services per week in January 1997. The majority of Speedlink services were local feeder workings between marshalling yards and individual terminals, reflecting the far greater number of locations served when compared to Enterprise. 


\section{Prospects for new terminals}

In Scotland, as Table 3 showed, there are many terminals that were still handling Speedlink wagonload consignments, but that have not re-opened to handle Enterprise traffic. At many of these locations the trackwork remains in place and the industry that was served by rail is still active, providing potential for greater expansion of Enterprise. There are also terminals that concentrated on dedicated services after Speedlink's demise, but which are now beginning to be served by Enterprise trips either in addition to, or instead of, trainload services. Clearly, though, the expansion of Enterprise is not simply mirroring the Speedlink network that existed prior to 1991. EWS has been careful not to attract unprofitable traffic, since the main flaw of the Speedlink network was the long distance lightly loaded trip workings which accounted for a high proportion of costs and was a major factor in its downfall. On the other hand, Enterprise services are now serving locations that have not seen rail traffic for many years, such as Georgemas Junction and Kyle of Lochalsh in the Scottish Highlands.

Railtrack has protected 90 sites across its network that it considers to be of strategic importance for growing the rail freight business, 16 of which are in Scotland (Railtrack, 1997). In addition, many locations that have lost their traffic flows in recent years still have connection agreements, so could feasibly see the resumption of services. In total, there are over 1700 locations across the network that Railtrack considers to be suitable for freight, so there is great 
potential for growth. Many redundant locations are unlikely to be reused for rail freight, however, because they served now extinct industrial developments.

During 1997, there was much evidence of new traffic flows emerging, primarily using the rapidly expanding Enterprise network. While some of the increased volume is accounted for by the expansion of existing flows (e.g. some of the timber flows) or the attraction of former Speedlink traffic (e.g. light fittings from Bodmin), much is new to rail, certainly in the time period under consideration. Perhaps the most significant of the new flows are the ones to and from the Far North Line, particularly aviation gas heading northwards and the significant southbound flow of refrigerators. The expansion of timber traffic has also been rapid and, in many cases, is using locations that have not previously dispatched timber, including direct loading of trains on the main line where sidings are not available. Timber is one commodity where significant growth is expected as a result of the large areas of forest in Scotland that will reach maturity in the next 10-20 years.

Growth has been taking place across Great Britain, both in terms of emerging wagonload traffic and also new trainload flows. Many of these new flows are on an ad hoc basis and as such differ quite significantly from recent years where the emphasis was on operating only regular timetabled services. As well as EWS' expansion of traffic volumes, Freightliner has recorded an increase in traffic in 1997. It has rapidly expanded its services, and indeed its network of terminals, and reported a $15 \%$ increase in volume compared to the previous year (Anon, 1997). 


\section{$\underline{\text { Journey time reductions }}$}

A significant development that has taken place in recent months has been an increase in operating speed for selected wagonload services. For many years now, Freightliner's container services have been operating at $75 \mathrm{mph}(120 \mathrm{~km} / \mathrm{h})$, with the new Channel Tunnel intermodal services also operating at this speed. Virtually all other freight services, however, have been limited to a maximum of $60 \mathrm{mph}(97 \mathrm{~km} / \mathrm{h})$ or less. With the introduction in 1997 of a $75 \mathrm{mph}(120 \mathrm{~km} / \mathrm{h})$ Anglo-Scottish Enterprise service, journey times have been reduced significantly. As Table 4 shows, time savings of around $40 \%$ between London and Glasgow have been achieved. This has been due to the greater operating speed combined with reductions in marshalling time en route. This new service is only available to certain traffic types though, since most current rolling stock cannot operate at $75 \mathrm{mph}(120 \mathrm{~km} / \mathrm{h})$. Much of the growth in wagonload traffic is expected to be intermodal, using equipment that can already run at this speed, and new wagons currently being considered for other traffic flows will be able to operate at $75 \mathrm{mph}(120 \mathrm{~km} / \mathrm{h})$.

(Insert Table 4 here)

These time savings mean that rail should be better able to compete with road for time-critical movements. An analysis of recent traffic gains, particularly on the Anglo-Scottish routes, reveals that there are flows that are traditionally assumed 
to be very time-critical. For example, Safeway successfully undertook trials between Daventry and Mossend using intermodal wagons carrying cargoes such as wine, mineral water and canned goods, with the establishment of a regular service expected in the near future. This has been followed by Superdrug, who have been using rail for the overnight transfer of a wide variety of toiletry products between Wakefield and Mossend. For much of their routes, these flows have been integrated with existing Enterprise services, meaning that requirements for extra resources and train paths are limited. These retail examples highlight the possibilities for rail to be used for the trunk haul, with road haulage handling the secondary movements.

\section{Conclusions}

It is evident that rail freight in Great Britain has being going through a period of significant change and it would appear that the prospects for gaining an increased market share are better at the current time than for many decades. This is evident from the variety of traffic flows gained during 1996/97, acceleration of selected wagonload services and expansion of both the Enterprise wagonload and Freightliner networks. Added to this are gains in traditional trainload flows of bulk materials. Privatisation has clearly had a major impact on the nature of rail freight operations but other changes, for example the increased willingness of industry to consider rail in the face of growing pressures on the road network and environment, are of importance. 
For rail to make a significant breakthrough in the movement of time-sensitive products, a market in which it currently has a minimal role but which has been growing at the expense of the bulk markets, it has to be able to respond to the demands placed on it by those who currently use road for virtually all, if not all, their transport requirements. In the absence of significant government intervention to discourage the use of road freight, it is only if it can meet these demands that it is likely to be able to achieve the three-fold increase in volumes that both EWS and RCEP are seeking. There is little evidence available to suggest that recent policy changes in road transport, for example the $6 \%$ increase in fuel duty per annum in real terms, have had any noticeable effects on the modal split for freight movements, though detailed research has not yet been carried out to assess any effects. An improved level of understanding of the modal choice decision making processes is required to enable identification of the effects of the key logistical trends and of any policy changes aimed at influencing the modal split. This would assist in determining the key areas where there may be potential for rail to increase its share of the market for freight traffic and as such will form the basis for further research.

\section{References:}

ANON, 1997, Freightliner 15\% up, Modern Railways, 54, 753.

DETR, 1998, Bulletin of Rail Statistics: Quarter3 1997/98, Department of the Environment, Transport and the Regions, SB (98) 9, March. 
FREIGHTMASTER, 1997, The Complete Guide to British Railfreight Operations (Swindon, U.K.: Freightmaster Publishing).

HEATON, J., 1997, The Enterprise culture, Modern Railways, 54, 566-570.

MARSDEN, C. J., 1984, BR and Private Owner Wagons (Shepperton, U.K.: Ian Allan).

NERA (1997), The Potential for Rail Freight, Report to the Office of the Rail Regulator, Prepared by National Economic Research Associates, The MVA Consultancy, Symonds Travers Morgan and the Institute for Transport Studies at the University of Leeds, September.

RAILTRACK, 1997, A Guide to Freight Connections, November (London, U.K.: Railtrack).

RHODES, M. and SHANNON, P., 1991a, The Freight Only Yearbook No. 2 (Kettering, U.K.: Silver Link Publishing Ltd).

RHODES, M. and SHANNON, P., 1991b, Freightfax: The Comprehensive Guide to BR Freight Today (Kettering, U.K.: Silver Link Publishing).

RCEP (ROYAL COMMISSION ON ENVIRONMENTAL POLLUTION), 1994, Transport and the Environment (London, U.K.: HMSO). 


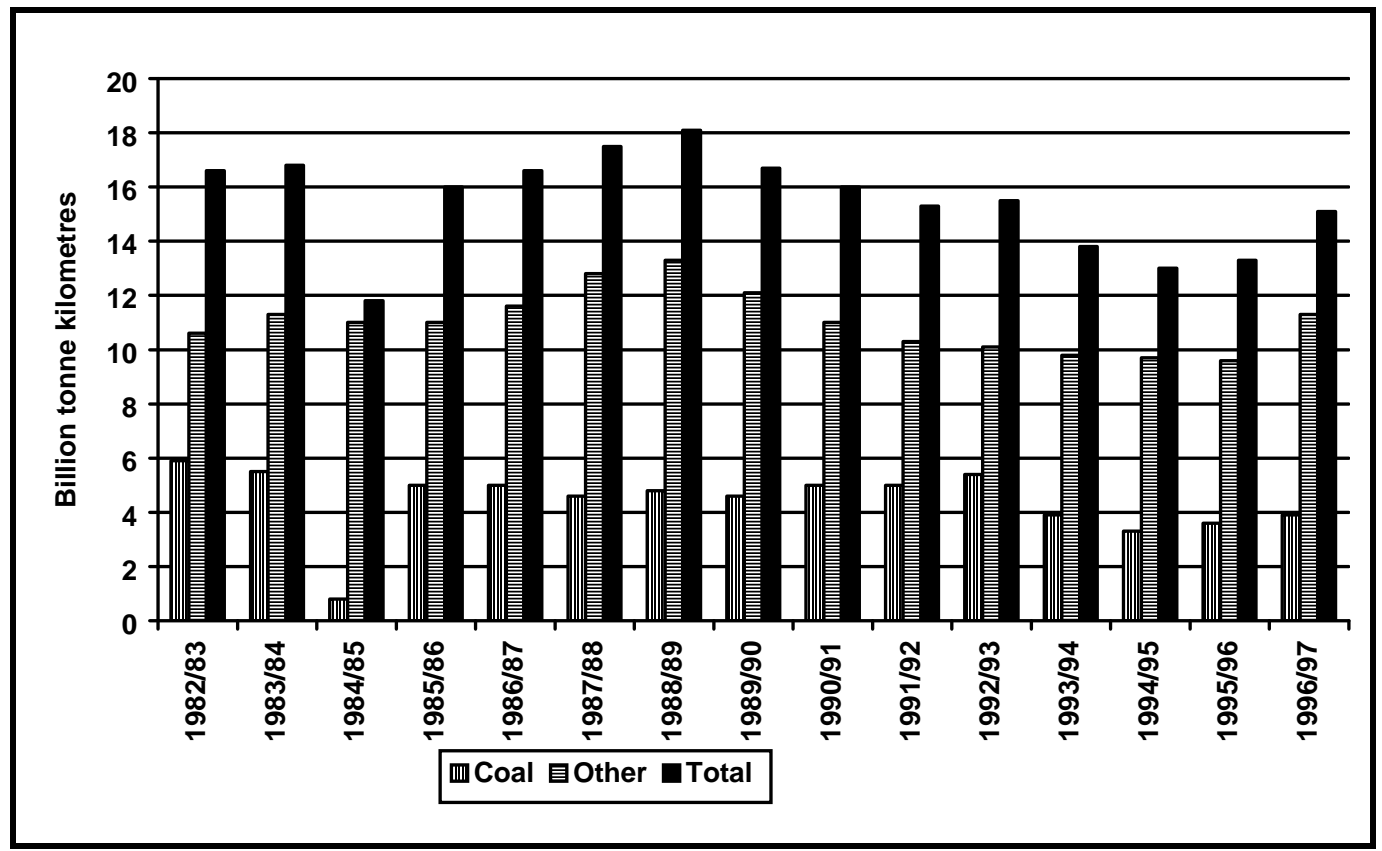

Source: DETR, Bulletin of Rail Statistics (1998)

Figure 1: Freight moved on national railways, Great Britain 1982/83 to $\underline{1996 / 97}$ 


\begin{tabular}{|l|c|c|c|}
\hline & 1991 & 1997 & $\%$ change \\
\hline \hline Database information (excl. coal): & & & \\
Total no. of database entries & 1471 & 1080 & $-27 \%$ \\
Approx. no. of loaded services per week & 3386 & 2316 & $-32 \%$ \\
Approx. tonnes lifted (millions) (annualised) & 81 & 56 & $-31 \%$ \\
\hline \hline Published annual statistics (excl. coal): & & & \\
Tonnes lifted by rail (millions) & 63 & 50 & $-21 \%$ \\
Tonne kilometres by rail (billions) & 11.0 & 11.3 & $+3 \%$ \\
\hline
\end{tabular}

Source: DETR, Bulletin of Rail Statistics (1998); original databases

Table 1: Database information and published statistics for rail freight, 1991 \& 1997 


\begin{tabular}{|l||c|c|c|}
\hline Commodity & 1991 & 1997 & $\begin{array}{c}\text { \% change } \\
(1991-1997)\end{array}$ \\
\hline \hline Construction & 529 & 362 & $-32 \%$ \\
\hline Metals & 633 & 356 & $-44 \%$ \\
\hline Petroleum & 314 & 184 & $-41 \%$ \\
\hline Container/intermodal/automotive & 696 & 786 & $+13 \%$ \\
\hline Other bulk & 119 & 107 & $-10 \%$ \\
\hline Non-bulk & 1095 & 521 & $-52 \%$ \\
\hline \hline Total & 3386 & 2316 & $-32 \%$ \\
\hline
\end{tabular}

Source: original databases

Table 2: Number of regular loaded railfreight services per week, by commodity 


\begin{tabular}{|l||c|c|c|}
\hline Commodity & 1991 & 1995 & 1997 \\
\hline \hline Construction & 9 & 4 & 4 \\
\hline Metals & 6 & 1 & 1 \\
\hline Petroleum & 14 & 6 & 6 \\
\hline Container/intermodal/automotive & 2 & 2 & 2 \\
\hline Non-bulk/other & 48 & 20 & 22 \\
\hline \hline Total* & 72 & 31 & 33 \\
\hline
\end{tabular}

Source: original databases

* - total may be less than sum of components due to some locations handling more than one commodity type

Table 3: Number of locations served by regular rail freight services in Scotland 


\begin{tabular}{|l|c|c|c|}
\hline & $\begin{array}{c}\text { 60mph } \\
\text { time (hrs) }\end{array}$ & $\begin{array}{c}75 \mathrm{mph} \\
\text { time (hrs) }\end{array}$ & $\begin{array}{c}\% \\
\text { change }\end{array}$ \\
\hline Mossend (Glasgow) - Wembley (London) & 12.75 & 8 & $-37 \%$ \\
\hline Wembley (London) - Mossend (Glasgow) & 13.5 & 8 & $-41 \%$ \\
\hline
\end{tabular}

Source: EWS, Freightmaster (1997) and railway publications

Table 4: Journey time reductions for Anglo-Scottish Enterprise services 